\title{
Circulating fluidized bed heat recovery/storage and its potential to use coated phase-change-material (PCM) particles
}

\author{
F. Pitié ${ }^{\mathrm{a}, \mathrm{b}}$, C.Y. Zhao ${ }^{\mathrm{c}}$, J. Baeyens ${ }^{\mathrm{b}}$, J. Degrève ${ }^{\mathrm{d}}$, H.L. Zhang ${ }^{\mathrm{d}, *}$ \\ ${ }^{a}$ Whittaker Engineering Ltd., Stonehaven, UK \\ ${ }^{\mathrm{b}}$ University of Warwick, School of Engineering, Coventry, UK \\ ' School of Mechanical Engineering, Shanghai Jiaotong University, Shanghai 200240, China \\ ${ }^{\mathrm{d}}$ Department of Chemical Engineering, Chemical and Biochemical Process Technology and Control Section, Katholieke Universiteit Leuven, Heverlee, Belgium
}

\section{H I G H L I G H T S}

- Within the thermal storage systems available or investigated, PCMs are the sole latent heat stores.

- PCMs have a high potential in energy capture and storage, using a circulating fluidized bed (CFB) as transfer/storage mode.

- Thermal considerations determine the optimum size range for the applied PCM particles $(<400 \mu \mathrm{m})$.

- The wall-to-CFB heat transfer is measured, and compared with both empirical and model predictions.

\section{A R T I C L E I N F O}

\section{Article history:}

Received 14 August 2012

Received in revised form 5 November 2012

Accepted 13 December 2012

Available online 8 February 2013

\section{Keywords:}

Heat transfer

Coated phase-change material

Convection

Conduction

Radiation

Solar energy collectors

\begin{abstract}
A B S T R A C T
Within the thermal energy capture and/or storage systems currently available or investigated, PCMs are the sole latent heat stores. Despite their low thermal conductivity, that limits charging and discharging times, the higher energy storage capacity per unit weight in comparison with sensible heat stores, makes them increasingly attractive for high temperature applications, resulting in reduced storage volumes and required circulation rates within the heat collector. The present paper introduces these PCMs, and their potential application in high temperature energy capture and storage, using a circulating fluidized bed (CFB) as transfer/storage mode. Thermal considerations determine the optimum size range for the applied particles $(<400 \mu \mathrm{m})$. The heat transfer from the wall of the CFB to the flowing gas-solid suspension is a major design parameter of the collector, and studied for different operating conditions as determined by the gas velocity and solids circulation flux. Measured values of the heat transfer coefficients are discussed, and compared with empirical predictions of Molodtsof-Muzyka, and Gorliz-Grace. Fair agreement is obtained only when the empirical parameters are carefully predicted. The application of a packet renewal mechanism at the wall is also investigated, with a fair prediction of the heat transfer coefficient in terms of the expected solid contact time at the wall.
\end{abstract}

(c) 2013 Elsevier Ltd. All rights reserved.

\section{Introduction}

\subsection{Phase change materials (PCMs)}

Latent heat thermal energy storage and associated phase change materials (PCMs) are attractive as they provide a high energy density storage due to the phase transformation, and mostly applied by solidification/fusion, or to a lesser extent by boiling/ condensing. PCMs can involve organic or inorganic materials, coated by (or embedded in) a stable and inert shell (or matrix). Various examples were recently reviewed by Fernandes et al. [1].

\footnotetext{
* Corresponding author.

E-mail address: Zhanghl.lily@gmail.com (H.L. Zhang).
}

Relative to sensible heat energy storage systems, a PCM requires a lower weight and volume of material for a given amount of stored energy and has the capacity to store the heat at a constant or near-constant phase-transition temperature. Considering the latent heat of phase transition and the sensible heat related to the specific heat capacity $\left(C_{p}\right)$ and the applied temperature difference $(\Delta T)$, it is obvious that an inorganic PCM can store the same amount of energy in $25-30 \%$ of the weight of a pure inorganic solid; whereas an organic paraffin-based PCM stores about seven times more energy per unit weight than the pure mineral or metal used to coat the paraffin. The main disadvantage with regards to PCMs is the low thermal conductivity and the phase change itself: during extraction of energy from storage, the liquid solidifies at the heat transfer surfaces and an immobile layer of solid material 


\section{Nomenclature}

$\begin{array}{ll}a, b & \text { dimensionless parameters } \\ A_{e x} & \text { surface area of the heat exchanging wall, } \mathrm{m} \\ \mathrm{Bi} & \text { Biot number } \\ \mathrm{C} & \text { solid to gas heat capacity, } C_{p} / C_{\mathrm{g}} \\ C_{p}, C_{g} & \text { specific heat capacity of solid and gas respectively, }\end{array}$

CAF, CFB, BFB core-annulus flow, circulating and bubbling fluidized bed, respectively

ID, OD inner and outside diameter respectively, $\mathrm{mm}$

$D \quad$ riser equivalent diameter, $\mathrm{m}$

$d_{p} \quad$ average particle diameter, $\mathrm{m}$

DRF, DRU dilute riser flow, dense riser flow, respectively

$f_{d} \quad$ time fraction of contact by the dense phase

$G \quad$ solids circulation flux, $\mathrm{kg} \mathrm{m}^{-2} \mathrm{~s}^{-1}$

$G_{s h} \quad$ particles horizontal exchange flux, $\mathrm{kg} \mathrm{m}^{-2} \mathrm{~s}^{-1}$

$h_{c} \quad$ contact transfer resistance, $\mathrm{W} \mathrm{m} \mathrm{m}^{-2} \mathrm{~K}^{-1}$

$h_{d} \quad$ heat transfer coefficient during dense phase contact, $\mathrm{W} \mathrm{m} \mathrm{m}^{-2} \mathrm{~K}^{-1}$

$h_{i j}^{\text {rad }} \quad$ radiation heat transfer coefficient, $\mathrm{W} \mathrm{m} \mathrm{m}^{-2} \mathrm{~K}^{-1}$

$h_{g}, h_{g c} \quad$ gas convective heat transfer coefficient, $\mathrm{W} \mathrm{m}^{-2} \mathrm{~K}^{-1}$

$h_{l} \quad$ heat transfer coefficient of lean gas phase contact, $\mathrm{W} \mathrm{m}^{-2} \mathrm{~K}^{-1}$

$h_{m}, h \quad$ average heat transfer coefficient from riser wall to the suspension, $\mathrm{W} \mathrm{m}^{-2} \mathrm{~K}^{-1}$

$h_{r} \quad$ heat transfer coefficient by radiation, $\mathrm{W} \mathrm{m}^{-2} \mathrm{~K}^{-1}$

$h_{s r} \quad$ heat transfer coefficient by radiation from the suspension to the wall, $\mathrm{W} \mathrm{m} \mathrm{m}^{-2} \mathrm{~K}^{-1}$ $h_{\text {tot }} \quad$ total effective heat transfer coefficient, $\mathrm{W} \mathrm{m} \mathrm{m}^{-2} \mathrm{~K}^{-1}$

$h(\bar{\theta}) \quad$ average heat transfer coefficient as function of contact time at the wall, $\mathrm{W} \mathrm{m} \mathrm{m}^{-2} \mathrm{~K}^{-1}$

$k_{g}, k_{p} \quad$ thermal conductivity of gas and particles, respectively, $\mathrm{W} \mathrm{m}^{-1} \mathrm{~K}^{-1}$

$M \quad$ loading ratio

$\mathrm{Nu}$, Re Nusselt and Reynolds number respectively

$r \quad$ radial position in a sphere of radius $R, \mathrm{~m}$

$T_{b}, T_{w} \quad$ bulk temperature and wall temperature respectively, $\mathrm{K}$

$T_{R}, T_{c} \quad$ temperature at the outer surface or core of a sphere, respectively, $\mathrm{K}$

$t_{g}, t_{p} \quad$ residence time of gas and particles, respectively, $\mathrm{s}$

TFBB Turbulent Fluidized Bed at the Bottom of the CFB riser.

$U, U_{T R} \quad$ superficial air velocity through the riser and transport velocity respectively, $\mathrm{m} \mathrm{s}^{-1}$

$\bar{v}_{p} \quad$ average velocity of particle, $\mathrm{m} \mathrm{s}^{-1}$

$\delta_{g} \quad$ gas gap thickness, $\mu \mathrm{m}$

$\Delta T \quad$ temperature difference, $\mathrm{K}$

$\alpha \quad$ thermal diffusivity of the particle $\left[k_{p} / \rho_{p} C_{p}\right], \mathrm{m}^{2} \mathrm{~s}^{-1}$

$\beta \quad$ heating rate, $\mathrm{K} \mathrm{s}^{-1}$

$\varepsilon \quad$ voidage of the riser

$\varepsilon_{\text {sus }} \quad$ cross sectional average suspension voidage

$\varphi \quad$ slip factor

$\bar{\theta} \quad$ average contact time of the particle packets at the wall, $\mathrm{s}$

$\rho_{g}, \rho_{p} \quad$ gas and particle density respectively, $\mathrm{kg} \mathrm{m}^{-3}$

$\rho_{\text {sus }} \quad$ suspension density, $\mathrm{kg} \mathrm{m}^{-3}$

$\zeta \quad \zeta=\sqrt{1.82 \log (\mathrm{Re})-1.64}$ Eq. (13) grows as it gives up its heat of fusion. Both factors lead to slow charging and discharging rates, hence contacting techniques with a high heat transfer rate are required.

Although the development of PCM applications is increasingly reported upon in the literature, the manufacturing of PCM-particles is at its early stage and commercial small-size particles are not yet available. Fundamental studies on PCM materials towards their properties and behaviour have been presented by Pitié et al. [2], Joulin et al. [3] and Li et al. [4]. Applications of PCM cold storage systems have been investigated by Castell et al. [5], Martin et al. [6], Rady [7] and Oró et al. [8]. Building applications have been assessed by e.g. Zhou et al. [9] and Borreguero et al. [10]. Additional research investigated the use of PCM materials in tubular heat exchangers [11-13] and in specific applications, such as in a finned storage [14] or in packed bed storage [7].

The potential of using a suspension flow of PCM-particles in energy capture/storage has not previously been assessed, and is studied in the present paper, with the main focus upon the dominant heat transfer mode and upon the heat transfer coefficients obtained in such a suspension flow system.

The variation of the surface heat flux depends upon the relative importance of the convective resistance (fixed resistance) and the conductive resistance (variable resistance). A dominant convective resistance achieves a nearly uniform surface heat flux with time, whereas a conductive resistance will create a time-decreasing heat flux. In view of the relative importance of convection and conduction, it is therefore important, as a first objective, to consider the heat transfer mode to the PCM particles, as discussed in Section 2. To achieve the dominant convection heat transfer, the analysis will determine that systems with a high heat transfer coefficient are required. The second objective of the research subsequently quantifies the heat transfer coefficients obtained between the wall of a CFB riser and the circulating gas-solid suspension of particles. This heat transfer coefficient is assessed in terms of the different hydrodynamic regimes that occur in a CFB riser. The high heat transfer coefficient obtained will demonstrate that convection heat transfer dominates.

\subsection{The CFB and heat transfer}

The circulating fluidized bed (CFB) is increasingly used in chemical reactors and in physical gas-solid processes (e.g. drying). Recent developments propose its use in concentrated solar energy capture/storage systems or industrial waste heat recovery, to replace thermal fluids or molten salts as transfer and storage medium [15]. A circulating fluidised bed consists of various essential components, i.e. (i) a riser where generally most of the important industrial reactions or thermal processes occur, (ii) a cyclone which separates solids from air, allowing only very fine solids to be carried out of the system; (iii) a standpipe to collect solids from the cyclone and provides a solids reservoir; and (iv) a solids re-circulation valve, that feeds solids back into the riser. The riser is the key part the CFB system. A CFB system commonly uses small Geldart A-Type particles, also used in the present experiments. The typical set-up of Fig. 1, applicable in solar towers [16] and in high temperature waste heat recovery, applies a dense particle bed conveyed within a tube bundle to capture the heat at bed temperatures between e.g. 500 and $750{ }^{\circ} \mathrm{C}$, thereafter using the stored heat in a subsequent bubbling fluidized bed steam boiler. A CFB shares many of its advantages with traditional bubbling fluidized beds (BFBs), including temperature uniformity and excellent heat transfer. The continuous carry-over of particles implies solids' collection and return equipment. In solar energy capture systems, solar heat will be captured at the outside tube wall, and subsequently transferred to the circulating solids. 


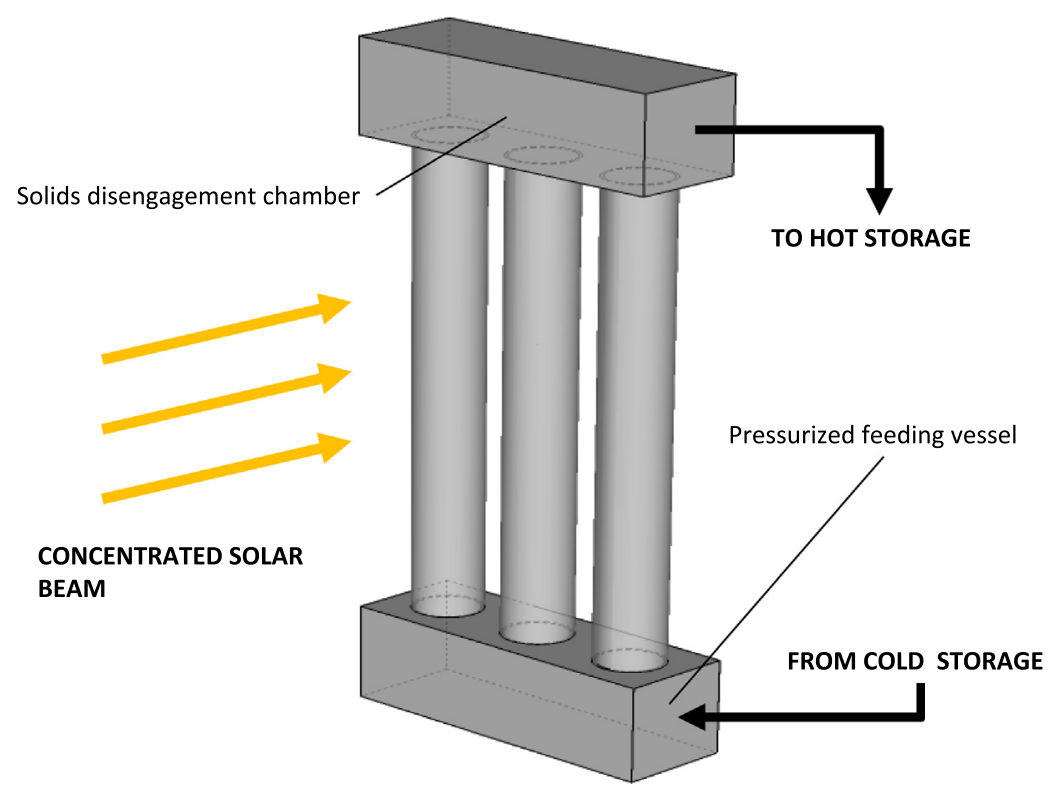

Fig. 1. Illustration of the riser solar energy capture and storage.

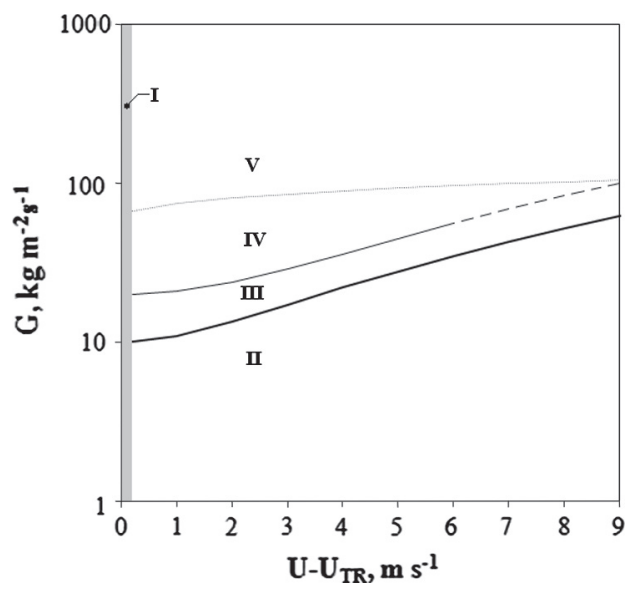

Zone I: Transition zone and/or inaccuracy in UTR prediction Zone II: dilute riser flow (DRF)

Zone III: core-annulus flow (CAF) only

Zone IV: CAF with turbulent fluidized bed at the bottom (TFBB)

Zone $\mathrm{V}$ : dense riser up-flow (DRU)

transition DRF - CAF: G = $10+(\mathrm{U}-\mathrm{UTR}) 1.8$

transition CAF - CAF with TFBB: $\mathrm{G}=20+(\mathrm{U}-\mathrm{UTR}) 2$

.........transition CAF with TFBB - DRU: $\mathrm{G}=60+15$ (U - UTR) 0.5

- - - Range of operating conditions where CAF mode is no longer reported and only DRF and DRU

prevail.

Fig. 2. Hydrodynamic operating modes of a CFB riser, expressed as $G$ versus $U-U_{T R}$ depending on the different hydrodynamic flow modes [17].

The riser operating modes are vital to design a CFB, since producing different solid residence times and mixing behaviour and determining the efficiency of the heat transfer. Fig. 2 depicts the existence of four different operating modes (dilute, dense, coreannulus, combined) as a function of $U$ and $G$ in the riser [16]. The various flow regimes have distinct characteristics towards solids flow. In general, the particle velocity is defined as:

$\bar{v}_{p}=\frac{U}{\varepsilon \varphi}$

In the Dilute Riser Flow (DRF)-regime, the slip factor, $\varphi$, has a previously reported value between 1 and 1.2 [16,17]. In Dense Riser Upflow (DRU), Chan et al. [17] found that the $\varphi$ values are fraction- ally higher, ranging between 1.2 and 1.6 with an average of 1.3. In Core-annulus Flow (CAF), cluster formation reduces the net velocity and $\varphi$ values are close to $2[17,18]$. CAF with Turbulent Fluidised Bottom Bed (TFBB) is an intermediate regime. The residence time for CAF with TFBB is significantly longer than CAF itself and DRF due to the existence of the fully mixed TFBB. Chan et al. [19] demonstrated that the residence time for solids in TFBB alone can range from 10 to $20 \mathrm{~s}$. The characteristics of the CAF region above the TFBB are similar to the above sole CAF flow, as described before. Together with the particle velocity, also the bed voidage is distinct, ranging respectively from about 0.99 in DRF; $0.7-0.9$ in a TFBB, 0.95-0.98 in CAF, to $\sim 0.9$ in dense riser up-flow DRU [20,21].

The design of a heat capturing CFB riser requires a prediction of the heat transfer coefficient between the wall of the riser and the 
particle-gas suspension flow. The wall-to-bed heat transfer coefficient will be measured for different operating conditions of gas flow $(U)$ and solids' circulation rate $(G)$ and will cover the different operating modes of the riser flow (dilute, core-annulus, dense), which will be shown to have a marked influence on the heat transfer coefficient.

Heat transfer to the wall of a CFB riser can be assumed to involve additive components due to conduction, convection and radiation, similar to that described for bubbling beds [22], different since no bubbles are present, but with the flow at the wall dominated by streamers or clusters travelling upward and downward. The processes governing heat transfer are however similar, with packets of particles contacting the wall, and exchanging heat according to the known film penetration model [22]. Published empirical correlations, widely used in bubbling fluidized beds, are not common for circulating fluidized beds. Instead, a number of semi-empirical models have been proposed in the literature and discussed below. As indicated in Eq. (2), one treats the heat transfer as being composed of additive conduction/convection and radiation.

$h_{\text {tot }}=f_{d} h_{d}+\left(1-f_{d}\right) h_{1}+h_{r}$

where $h_{\text {tot }}, h_{d}, h_{l}$ and $h_{r}$ are the total effective heat transfer coefficient, the heat transfer coefficient during dense (particle) phase contact, the heat transfer coefficient during lean gas phase contact, and the heat transfer coefficient for radiation, respectively, while $f_{d}$ is the time fraction of contact by the dense phase [22,23].

Previous work on heat transfer in vertically flowing gas-solid suspensions, as occurring in a CFB riser, has been extensively reviewed by Muzyka [24] and Grace [25]. As long as convective heat transfer between the suspension and the surface is considered, with the exclusion of radiant heat transfer, the major concern is to predict the variation of the heat transfer coefficient with solids loading and gas velocity in various riser geometries. Different empirical correlations and models (mostly for bed-to-wall heat transfer) have been proposed, but Grace [25] summarised the situation as follows: "no existing correlations give consistent agreement with the available data".

The theoretical approach proposed by Molodtsof and Muzyka [26] predicts the wall-to-suspension heat transfer coefficient $\left(h_{m}\right)$ as a function of loading ratio $(M)$, heat capacity ratio $(C)$, and the gas convective transfer coefficient $\left(h_{g}\right)$.

$\frac{h_{m}}{h_{g}}=\frac{(1+M C)^{2}}{1+a M C+b(M C)^{2}}$

The dimensionless parameters $a$ and $b$ in Eq. (3) are compound factors involving dimensionless radial concentration, velocity, and temperature profiles. They are generally unknowns, as the profiles are unknown. Apart from design parameters (pipe diameter, particle size distribution and physical properties), they only depend on the superficial gas velocity, and need to be fitted from experimental results for the specific gas-solid system under scrutiny.

Golriz and Grace [27] proposed a model for large units ( $>1 \mathrm{~m} \mathrm{ID)}$ based on the assumptions of fully developed conditions and radially uniform clusters at the wall, hence valid for CAF operation. At any instant, some portions of the surface are bare, while other portions of the surface are covered by clusters, each separated from the wall by a thin gas gap of thickness $\delta_{g}$. Different heat transfer mechanisms are assumed for the bare and covered portions. For the bare sections, transfer is by gas convection (denoted by subscript ' $g c$ ') and by radiation from the suspension to the wall (subscript ' $s r^{\prime}$ ). The rest of the wall is covered by clusters/streamers providing a parallel transfer path. The transfer rate is then assumed to be controlled by a particle horizontal exchange flux, $G_{s h}$. The combined expression of the heat transfer coefficient is given as a total heat transfer coefficient, $h_{t o t}$, as follows:

$h_{\text {tot }}=\left(h_{g c}+h_{s r}\right)(1-f)+\frac{f}{\frac{1}{G_{s h} C_{p}+h_{b e}^{\text {rad }}}+\frac{1}{\left(k_{g} / \delta_{g}\right)+h_{e w}^{r a d}}}$

For operation at temperatures below $600{ }^{\circ} \mathrm{C}$, the radiation contribution can be omitted [22]. The parameters of the equation are then estimated, with an expression for the fractional coverage, $f$, accounting for the scale of the unit:

$f=1-\exp \left[-25000\left(1-\frac{2}{\exp (0.5 D)+\exp (-0.5 D)}\right)\left(1-\varepsilon_{\text {sus }}\right)\right]$

where $D(\mathrm{~m})$ is the riser equivalent diameter $(4 \times$ cross sectional area/perimeter). For large units, $f$ approaches unity, meaning that the entire wall becomes covered by clusters. The gas convective transfer coefficient, $h_{g c}$, was obtained from the well-known Dittus-Boelter correlation. If a contribution by radiation between the suspension and the bare wall is important, its contribution can be predicted as proposed in the Gorliz and Grace paper [27], or by an alternative estimation as presented in Section 5.5. of the present paper.

The gas gap thickness is estimated [28] from:

$\delta_{g}=0.0282 d_{p}\left(1-\varepsilon_{\text {sus }}\right)^{-0.59}$

where $d_{p}$ is the average particle diameter and $\varepsilon_{s u s}$ is the cross sectional average suspension void fraction. An expression for the lateral solids flux was obtained by fitting all heat transfer data for units of $D \geqslant 1 \mathrm{~m}$ where the suspension densities, $\rho_{\text {sus }}=\rho_{p}\left(1-\varepsilon_{\text {sus }}\right)+\rho_{g} \varepsilon_{\text {sus }}$, exceeded $5 \mathrm{~kg} \mathrm{~m}^{-3}$, leading to:

$G_{\text {sh }}=0.0225 \ln \left(\rho_{\text {sus }}\right)+0.1093$

Since the heat transfer is determined by the transient heat transfer from the wall to clusters of particles in contact, a surface renewal model can be applied, as initially developed by Baeyens and Geldart [22] for BFB applications.

$h(\bar{\theta})=\frac{h_{c}}{1+\frac{6 h_{c}}{\rho_{p} c_{p} d_{p}} \bar{\theta}}$

\section{The heat transfer mode and possible reduction of thermal gradients}

The present section assesses objective 1 of the study: "how can thermal gradients in and around the particle be avoided?" Application of the basic principles of both heat transfer to the particle and of heat conduction within the particle, allows to determine the required working conditions. The temperature uniformity throughout the particles can be determined by the heat conduction law of Fourier, here applied in non-stationary regime and for the simple case of a spherical particle:

$\frac{\partial T}{\partial t}=\frac{k_{p}}{\rho_{p} c_{p}}\left(\frac{\partial^{2} T}{\partial r^{2}}+\frac{2}{r} \frac{\partial T}{\partial r}\right)$

with symbols defined in the Nomenclature.

$\partial T / \partial t=\beta$ for $r=0$ to $R\left(=d_{p} / 2\right)$ and $\partial T / \partial r=0$ for $r=0$ (in the core)

The solution is given by Carslaw and Jaeger [29] as:

$\Delta T_{\max }=\left(T_{R}-T_{c}\right)=\beta d_{p}^{2} /(24 \alpha)$

Applied for various values of $\beta$ and with e.g. the characteristic properties of an inorganic particle at $773 \mathrm{~K}$, i.e. $k_{p}=0.60 \mathrm{~W} \mathrm{~m}^{-1}$ $\mathrm{K}^{-1}, c_{p}=1150 \mathrm{~J} \mathrm{~kg}^{-1} \mathrm{~K}^{-1}$ and $\rho_{p}=2800 \mathrm{~kg} \mathrm{~m}^{-3}$, results are a set of curves in function of the diameter as shown in Fig. 3. 


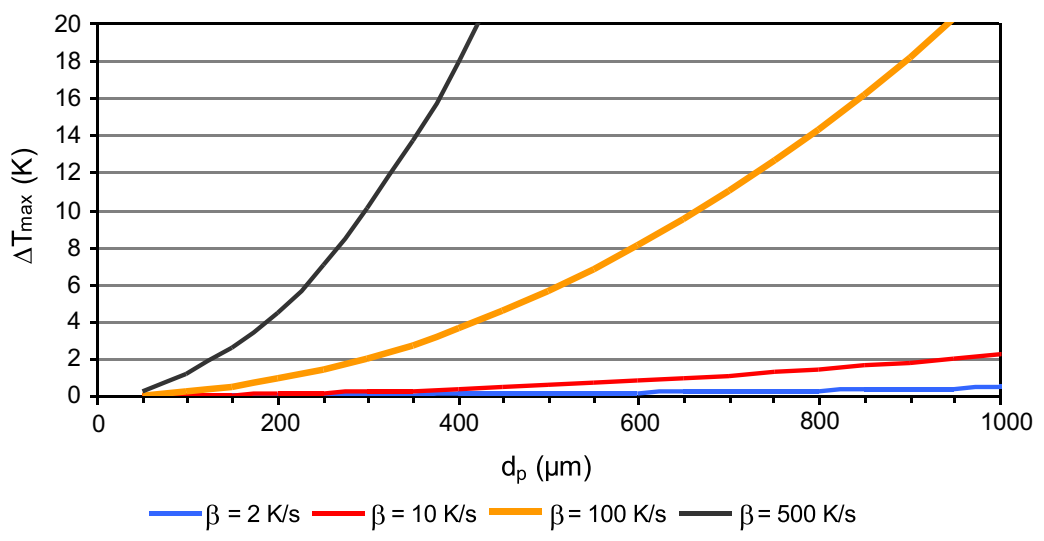

Fig. 3. Maximum temperature difference $\left(\Delta T_{\max }\right)$ between the surface and core of the particle in function of the particle diameter at different heating rates $(\beta)$.

These calculations show that the temperature differences between the particle surface and core are very limited, certainly when considering that the surrounding temperature is $773 \mathrm{~K}$.

The heating rate will vary with the heating technique applied, between minimally $1.5 \mathrm{~K} \mathrm{~s}^{-1}$ in a TGA (thermogravimetic analysis), to $>>100 \mathrm{~K} \mathrm{~s}^{-1}$ in a BFB or CFB [22]. In order to minimise $\Delta T_{\max }$ $(<10 \mathrm{~K})$ even at high heating rates, it is appropriate to use small inorganic particles (sand, $\mathrm{SiC}$, etc.) below $400 \mu \mathrm{m}$. No significant thermal gradient will occur in these small particles, even when working at slow heating rates: the core and the surface of the particle will behave thermally in a similar way.

Solar energy capture and subsequent heat release require a fast heat transfer from the exchanger wall to/from the particles. This heat transfer is conditioned by the degree of gas and solid turbulence achieved in the collector. The heat transfer coefficient depends on the gas-solid contacting mode. It ranges from $10 \mathrm{~W} \mathrm{~m}^{-2} \mathrm{~K}^{-1}$ for a static bed, to $50-100 \mathrm{~W} \mathrm{~m}^{-2} \mathrm{~K}^{-1}$ in a fixed bed with forced gas circulation (as in TGA), and several hundreds of $\mathrm{W} \mathrm{m}^{-2} \mathrm{~K}^{-1}$ for BFB and CFB [22]. This explains why fluidized beds are specifically considered as top technologies for solar energy systems. The value of the heat transfer coefficient in a CFB was previously reported between 150 and $600 \mathrm{~W} \mathrm{~m}^{-2} \mathrm{~K}^{-1}$. The experimental results of the present research are given in Section 4 below,

Since not only external convection but also internal conduction is important, the overall picture is expressed by the Biot-number, as the ratio of the internal resistance to heat penetration and the external convection resistance to heat transfer.

$B i=\left(d_{p} / k_{p}\right) /(1 / h)$

For the $100 \mu \mathrm{m}$ particle at $773 \mathrm{~K}$, the values are as follows:

$$
\begin{array}{lll}
h=150 \mathrm{~W} \mathrm{~m}^{-2} \mathrm{~K}^{-1} & \mathrm{Bi}=100.10^{-6} . & 150 / 0.60=0.025 \\
h=300 \mathrm{~W} \mathrm{~m}^{-2} \mathrm{~K}^{-1} & \mathrm{Bi}=100.10^{-6} . & 300 / 0.60=0.05 \\
h=500 \mathrm{~W} \mathrm{~m}^{-2} \mathrm{~K}^{-1} & \mathrm{Bi}=100.10^{-6} . & 500 / 0.60=0.08
\end{array}
$$

The Biot-number is $<<1$ in all cases, implying that the external resistance associated with convection heat transfer largely dominates for smaller particles. This remains valid for particle sizes below $\sim 700 \mu \mathrm{m}$. Bi is only $>1$ for coarser particles. This result confirms Fig. 3 where limited increasing $\Delta T_{\max }$ values are noticed with increasing $\beta$ values (achieved at high convection heat transfer rates), for smaller particles, but significant differences occur for coarser particles. Operating a CFB collector at $d_{p}<\sim 400 \mu \mathrm{m}$ is hence certainly indicated to avoid thermal gradients within the particle. Fortunately, CFB operations are restricted to particle sizes of similar magnitude [16].

\section{Experimental setup and procedure: wall-to-bed heat transfer}

The experimental riser and CFB are depicted in Fig. 4.

The riser consists of a $50 \mathrm{~mm}$ ID pipe approximately $2.5 \mathrm{~m}$ high. Solids circulation was achieved via a $100 \mathrm{~mm}$ ID downcomer and $50 \mathrm{~mm}$ ID L-valve. Air is supplied through a distributor plate and leaves the system through a cyclone after the riser exit. Pressure taps are located along the height of the riser and connected to a data acquisition system. Flow rates and pressure drops were monitored. A concentric wall heater of $10 \mathrm{~cm}$ length was installed at $1.2 \mathrm{~m}$ above the re-entry joint of the L-valve. Heat supply was by hot water $\left(60-90^{\circ} \mathrm{C}\right)$ or by thermal fluid (Santotherm 350). The downcomer was water-cooled through a $0.2 \mathrm{~m}$ long concentric cooler. The bed temperature was kept within the range of 30$40{ }^{\circ} \mathrm{C}$. The wall surface temperature was measured using a resistance thermocouple welded onto the wall. Additional Thermocoax thermocouples $(0.1 \mathrm{~mm}$ OD) were installed at various locations in the riser and downcomer, as well as in the feeding and overflow lines of the fluid, as indicated in Fig. 4. The flow rates of gas and solids were set to the desired values, the heat input into the system was fixed, and the system was allowed to stabilize over a period of about one hour, during which flow rate, temperatures, and pressures were monitored and recorded.

The axial pressure profile was recorded during each experiment in order to make sure that the suspension entering the heated section was in fully developed flow conditions. From the known exposed surface area, $A_{e x}$, and measured wall-to-bed temperature difference, $\Delta T$, the heat transfer coefficient was calculated for the given heat input as:

$h_{m}=\frac{Q}{A_{e x} \Delta T}$

The measurements were performed for the gas flow alone $\left(h_{g}\right)$ and for the gas-solid suspension at various solid/gas ratios $\left(h_{m}\right)$. The heat transfer coefficient to the gas-solid suspension, $h_{m}$, was also expressed as $h_{m} / h_{g}$ ratio. The bed material used was rounded sand of the following characteristics: $d_{s v}=75 \mu \mathrm{m}, \rho_{p}=2260 \mathrm{~kg} /$ $\mathrm{m}^{3}$, and $C_{p}=1.05 \mathrm{~kJ} / \mathrm{kg} \mathrm{K}$.

Various combined $(U, G)$ values were tested in order to scan the different riser hydrodynamic regimes: these experimental conditions are illustrated in Fig. 5, using the Mahmoudi et al. [16] regime diagram as a basis. Clearly DRF, CAF and DRU hydrodynamic regimes were investigated. 


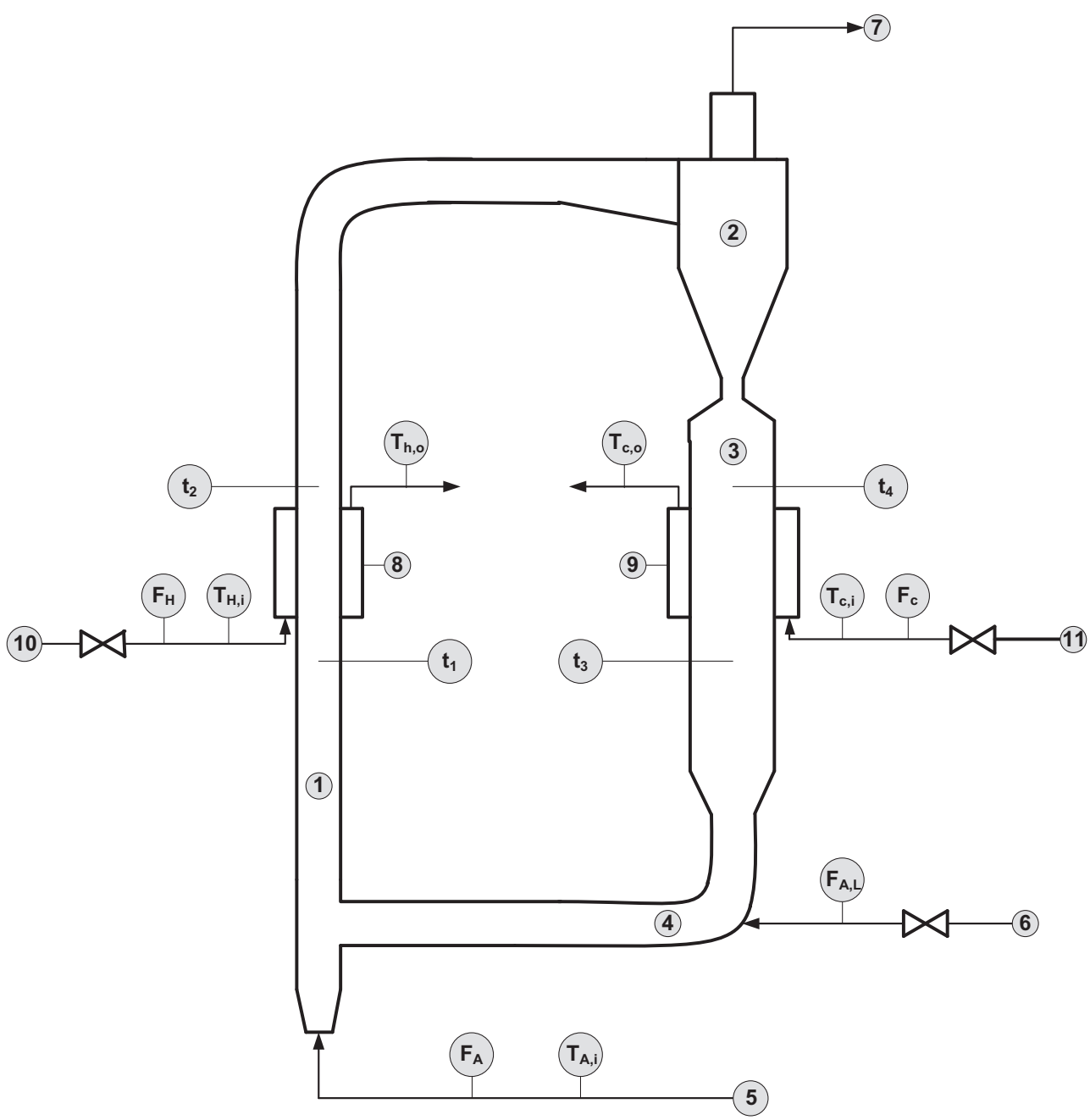

(1) riser $50 \mathrm{~mm}$ I.D., (2) HE Stairmand cyclone, (3) downcomer $100 \mathrm{~mm}$ I.D.,(4) L-valve $50 \mathrm{~mm}$ I.D., (5) air from speed-controlled blower, (6) compressed air, (7) vent to baghouse filter, (8) co-axial heating section, (9) co-axial cooling section, (10) supply of thermal fluid, (11) supply of cooling water; $\mathrm{F}_{\mathrm{H}}, \mathrm{F}_{\mathrm{C}}, \mathrm{F}_{\mathrm{A}}, \mathrm{F}_{\mathrm{A}, \mathrm{L}}$ : respectively flow meters of thermal fluid, cooling water, riser air, L-valve air; $\mathrm{T}$ : temperature probes for respective fluids; $t$ : temperature probes inside riser and downcomer.

Fig. 4. Layout of the experimental set-up.

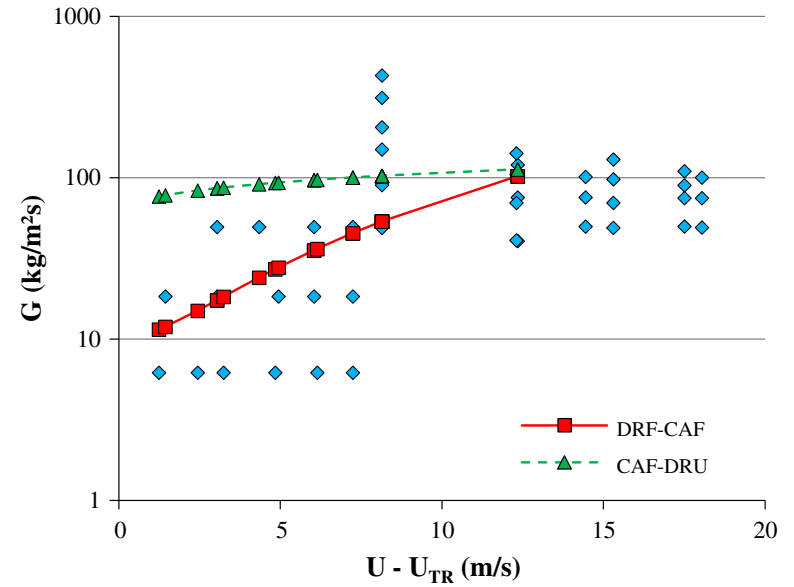

Fig. 5. Experimental $(U, G)$ conditions in comparison with the riser flow modes.

\section{Results and discussion}

\subsection{The gas convection coefficient}

Essential in the use of the semi-experimental equations, is the prediction of the heat transfer coefficient when solids are absent, i.e. the heat transfer coefficient between the heat transfer surface and a pure gas flow at velocity $U$, in the riser, $h_{g}$. The Gnielinski equation [30] is used to predict $h_{g}$ in the present treatment, to cover gas flow in the transitional and turbulent flow regime.

$\mathrm{Nu}=\frac{h_{g} D}{k_{g}}=\frac{\left(\frac{\zeta}{8}\right)(\mathrm{Re}-1000) \operatorname{Pr}}{1+12.7 \sqrt{\frac{\zeta}{8}\left(\operatorname{Pr}^{2 / 3}-1\right)}}\left(1+\left(\frac{D}{L}\right)^{2 / 3}\right)$

with $\zeta=\sqrt{1.82 \log (\operatorname{Re})-1.64}$ and other symbols defined in the Nomenclature. 
4.2. Experimental results for the riser-wall to bed heat transfer coefficient, $h_{m}$

Experimental results, expressed as the ratio of $h_{m} / h_{g}$, are illustrated in Fig. 6. Clearly, $h_{m}$ is a strong function of the $(U, G)$ combination, especially at lower $G$ values, thus also of the hydrodynamic operating mode of the riser. Experimental results will further be developed in terms of the empirical and model approaches of Section 1.2. At $G=0, h_{m}$ should assume the $h_{g}$ heat transfer coefficient, only a function of $U$.

\subsection{Preliminary literature findings}

In a previous research, Everaert et al. [31] studied the heat transfer coefficient to an in-bed heat transfer surface in a $0.1 \mathrm{~m}$ I.D. riser. Experiments were carried out in the DRF and CAF operating modes. Relevant results with respect to the present research determine that: (i) the core region extends to approximately $85 \%$ of the riser radius $(0.05 \mathrm{~m})$ with an annulus thickness of approximately $7.5 \mathrm{~mm}$; (ii) increasing the gas flow rate at a given solid circulation rate significantly reduces the suspension heat transfer coefficient; (iii) the heat transfer coefficient is a function of the radial position in the riser, as illustrated in Fig. 6: the heat transfer coefficient in the core is significantly higher than at the wall; and (iv) even in dilute flow, i.e. at the low $G$ values of Fig. 7, the solids contribute significantly to the overall heat transfer coefficient, since the ratio $h_{m} / h_{g}$ exceeds $\sim 2$.

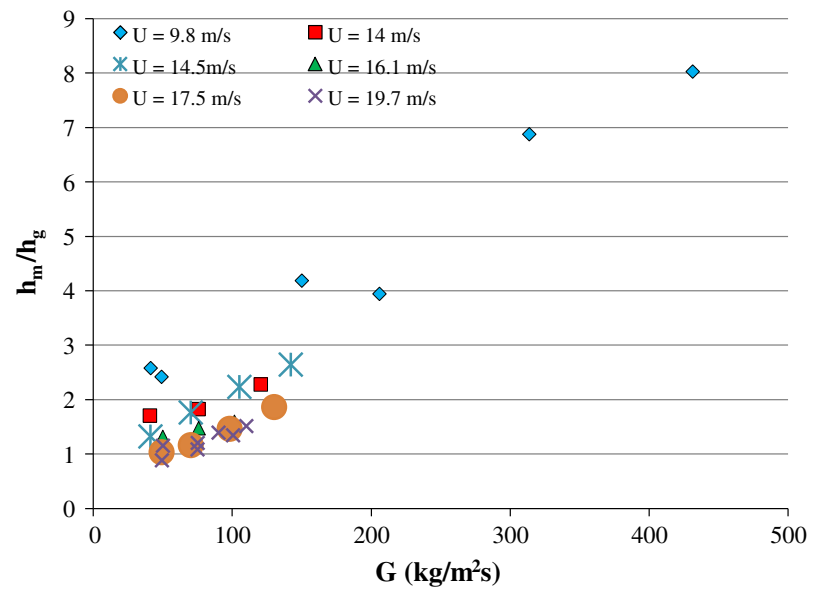

Fig. 6. Experimental results, expressed as $h_{m} / h_{g}$, for different $(U, G)$ combinations.

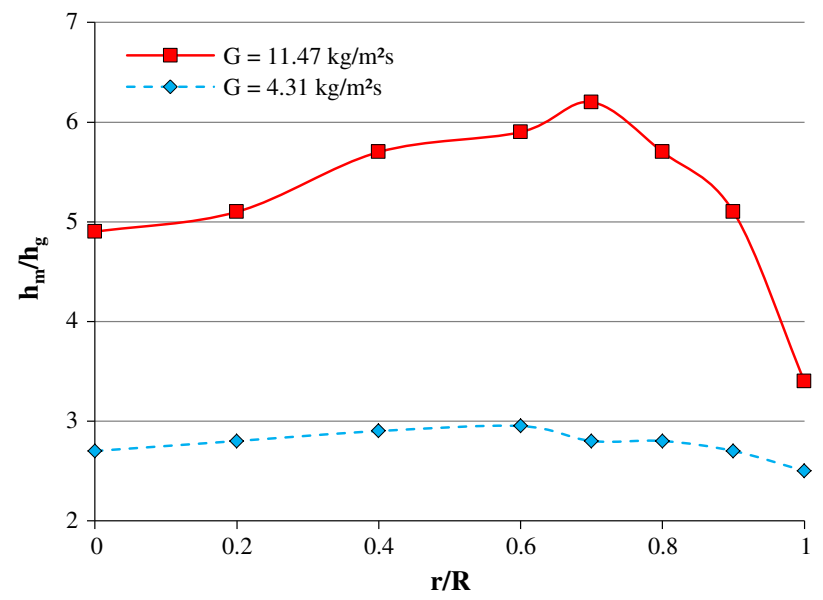

Fig. 7. Effect of the radial position of the heater in the riser on the heat transfer coefficient $h_{m}$ (expressed as ratio) at $U_{g}=7.8 \mathrm{~m} / \mathrm{s}$.

\section{Transformation of experimental results into design equations}

\subsection{Molodtsof and Muzyka}

All results were expressed as $h_{m} / h_{g}$ values. Experimental $h_{m} / h_{g^{-}}$ ratios can be fitted by Eq. (6), to determine the unknown coefficients $a$ and $b$.

Since the solid-to-gas heat capacity was constant in our experiments, the results could be used to define coefficients $a$ and $b$ (which remain constant in the range of gas velocities and solids loadings) and thereafter predict $h_{m} / h_{g}$ for various values of $M$ and $C$. The results are given in Fig. 8, illustrating the fair agreement obtained, with coefficients $a$ and $b$ respectively 3.37 and 0.028 $\left(R^{2}=96.5 \%\right)$. Of course, the design application of the Molodtsof and Muzyka approach needs the experimental determination of the fitting coefficients $a$ and $b$.

\subsection{Golriz and Grace}

The empirical equations of Golriz and Grace [27]can be transformed into the following equation, when radiation is neglected.

$\frac{h_{m}}{h_{g}}=(1-f)+\frac{f}{\left(\frac{1}{G_{s h} C_{p}}+\frac{1}{k_{g} / \delta_{g}}\right)}$

The suspension density and particle residence time $\left(t_{p}\right)$ were calculated according to Chan et al. [19]. The values of the gas residence time $\left(t_{g}\right)$ was calculated by the method presented in Mahmoudi et al. [32], thus a function of $U$ and $G$.

$\varepsilon_{\text {sus }}=\frac{U t_{g}}{U t_{g}+G t_{p} / \rho_{p}}$

$\rho_{\text {sus }}=\varepsilon_{\text {sus }} \rho_{g}+\left(1-\varepsilon_{\text {sus }}\right) \rho_{p}$

Although outside the range of applicability of the initial Gorliz and Grace correlations (experimental $D \ll 1 \mathrm{~m}$ ), the comparison between experimental and predicted values is illustrated in Fig. 9A. Since Golriz and Grace only deal with CAF applications $\left(G \lesssim 100 \mathrm{~kg} / \mathrm{m}^{2} \mathrm{~s}\right)$, the experimental results of the CAF regime were only used for the comparison. The deviation is between $\sim 250 \%$ and $400 \%$. This deviation is not only due to the scale of the riser, but also inherently linked to the required calculation of the underlying empirical parameters. The Gorliz-Grace equations are indeed very sensitive to the predicted value of $G_{s h}$.

A very fair agreement of the experimental and predicted heat transfer coefficient ratios, covering all of the different CFB operat-

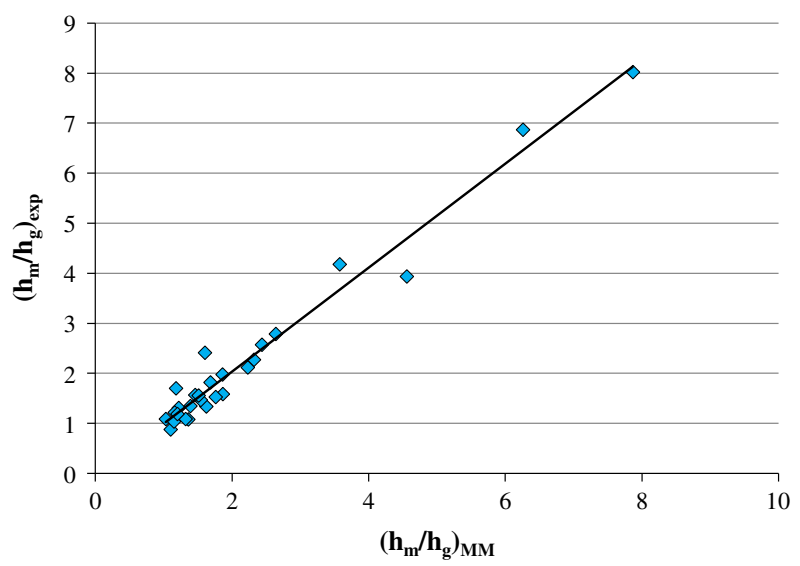

Fig. 8. Comparison of experimental and Molodstof-Muzyka (MM) predicted values of $h_{m} / h_{g}$. 


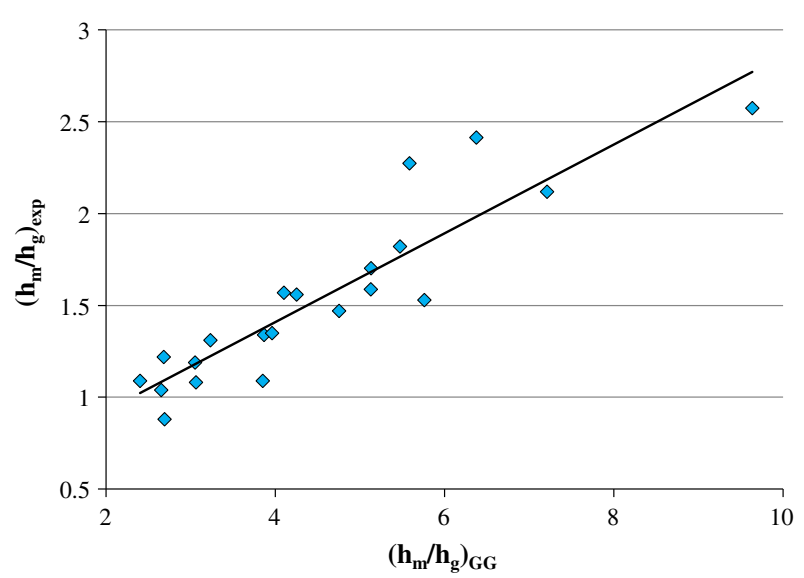

Fig. 9A. Comparison of experimental and Golriz-Grace (GG) predicted values of $h_{m} /$ $h_{g}$ (for $G \lesssim 00 \mathrm{~kg} / \mathrm{m}^{2} \mathrm{~s}$ ), according to the estimated parameters of the initial equations.

ing regimes, was obtained by using a modified dependency of $G_{s h}$ and $\rho_{\text {sus }}$ according to:

$$
\begin{aligned}
G_{\text {sh }} & =0.014 \text { for } \rho_{\text {sus }} \\
& \geq 12 \mathrm{~kg} \mathrm{~m}^{-3}, \text { hence in the DRU operating mode }
\end{aligned}
$$

And $G_{\text {sh }}=0.014+0.006\left(12-\rho_{\text {sus }}\right)$ for $\rho_{\text {sus }}<12 \mathrm{~kg} \mathrm{~m}^{-3}$

When applying these $G_{s h}$ values, a very good fitting is obtained, as illustrated in Fig. 9B.

\subsection{Surface renewal model}

Comparing experimental $h_{m}$ values with predictions using Eq. (8) enables the determination of the required fitting $\bar{\theta}$. This $\bar{\theta}$ value is represented in Fig. 10, the fitting value of $\bar{\theta}$ and the trend of its dependency on $(U, G)$ again stresses the importance of the riser operating mode. At high values of $G$, irrespective of $U$, the riser operates in the DRU (dense upwards flow) mode, and the contact time is determined by the prevailing solids velocity. This velocity is close to the operating gas velocity: according to Eq. (5) with $\varepsilon \sim 0.9$ and $\varphi \sim 1.3, \bar{\theta} \sim 0.1 \mathrm{~s}$. This particle velocity defined contact time is in fair agreement with the calculated fitting time.

In the CAF regime, for $G \lesssim 100 \mathrm{~kg} / \mathrm{m}^{2} \mathrm{~s}$, the contact time is a function of the downward velocity, normally assumed to be close to the terminal velocity of the particles, i.e. $0.38 \mathrm{~m} / \mathrm{s}$ for the tested

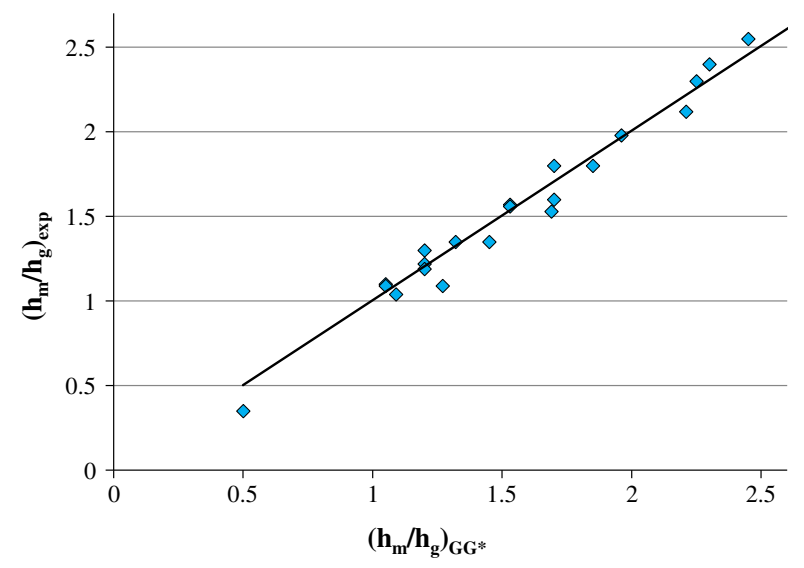

Fig. 9B. Comparison of experimental and Golriz-Grace (GG) predicted values of $h_{m} /$ $h_{g}$, according to $G_{s h}$ predictions of Eqs. (17) and (18).

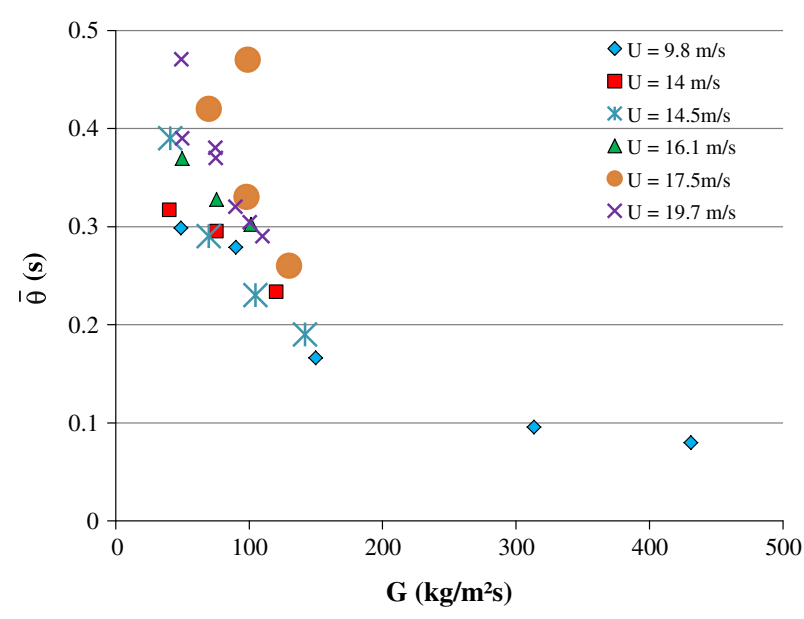

Fig. 10. Fitting contact time $\bar{\theta}$ for different combinations of $U$ and $G$.

particles. For the heater length of $0.1 \mathrm{~m}$, the contact time should hence be close to $0.26 \mathrm{~s}$, again in fair agreement with the experimental fitting results. The application of the contact time approach therefore certainly merits further investigations. These will combine heat transfer measurements and particle residence time measurements by Positron Emission Particle Tracking. These experiments are programmed and will be subsequently reported upon.

\subsection{Contribution of radiant heat transfer}

The effects of an increasing temperature are twofold:

(i) The particle convective heat transfer coefficient will increase due to the increasing thermal conductivity of the gas phase, included in the contact transfer resistance, $h_{c}$, of Eq. (8). In general [22], the convective heat transfer coefficient will increase proportional to $\sqrt{k_{g}}$.

(ii) At $T>600^{\circ} \mathrm{C}[22]$, radiation itself becomes important and can be calculated by using the well-known Stefan-Boltzman equation. In general, the contribution of radiation to the overall total heat transfer coefficient will increase from $\sim 10 \%$ at $600{ }^{\circ} \mathrm{C}$ to $\sim 20 \%$ at $800{ }^{\circ} \mathrm{C}[22]$.

Both the effects of $k_{g}$ and of radiation from wall-to-bed will significantly increase the heat transfer coefficient at bed temperatures of $500-750^{\circ} \mathrm{C}$ and wall temperatures $>850^{\circ} \mathrm{C}$, as encountered in solar energy capture beds.

\subsection{The advantages of using PCM-particles in the CFB solar energy capture}

Despite the excellent heat transfer coefficient to common heat carrier particles such as sand or $\mathrm{SiC}$, these systems suffer from some drawbacks, being mainly: (i) the progressive increase in bed temperature as the particles are conveyed from the inlet of the riser $\left(500{ }^{\circ} \mathrm{C}\right)$ to its outlet $\left(750^{\circ} \mathrm{C}\right)$, thus progressively reducing the driving heat transfer temperature difference between wall and bed; and (ii) the sole heat capture in the form of sensible heat, where the amount of heat to be removed, $(Q)$, necessitates a high circulation rate $(\mathrm{kg} / \mathrm{h})$ of particles, being $Q / C_{p}\left(T_{\text {out }}-T_{\text {in }}\right)$. High circulation rates involve high associated conveying operation costs.

When using PCM-materials, (i) the bed temperature will achieve its (constant) maximum at the temperature of fusion of the PCM, thus maintaining a slightly higher driving temperature difference; but most importantly, and (ii) sensible and latent heat 
(of fusion) will take part in absorbing $Q$ thus reducing the required circulation rate of particles by a factor of $\gtrsim 3$ at the given temperature ranges. This significant reduction also reduces the required conveying power and associated costs by the same factor. The development of PCM-coated particles, that can withstand both the thermal stress of temperature and phase variations, but also the erosive nature of the CFB is of paramount importance, and currently investigated. According to the results of the present research, these PCM particles, still to be developed and manufactured, should be of particle size well below $400 \mu \mathrm{m}$ to avoid the internal conduction resistance, while offering advantages of a high composite specific heat capacity, affecting both the heat capacity ratio, $C$, in the Molodtsof-Muzyka Eq. (3), and the denominator of Eqs. (7) and (8).

\section{Conclusions and recommendations}

Within the thermal energy capture and/or storage systems currently available or investigated, PCMs are the sole latent heat stores. The present paper introduces these PCMs, and their potential application in high temperature energy capture and storage, using a circulating fluidized bed (CFB) as transfer/storage mode. Thermal considerations determine the optimum size range for the applied particles $(<400 \mu \mathrm{m})$, when convection heat transfer dominates. In the design of a CFB heat collector, the heat transfer coefficient between the riser wall and the flowing suspension is an important design parameter to determine the required heat exchange surface area. The present research measured the wall-tobed heat transfer coefficient in the riser, with values of $\sim 60 \mathrm{~W} \mathrm{~m}^{-2} \mathrm{~K}^{-1}$ at low $G$ and high $U$ values, and up to $350 \mathrm{~W} \mathrm{~m}^{-2}$ $\mathrm{K}^{-1}$ at higher $G$ values. The ratio of the suspension heat transfer coefficient and the convective transfer coefficient for the sole gas flow, is confirmed as a valid fitting parameter. Experimental results are expressed in terms of this ratio. The application of Molodtsof and Muzyka requires the determination of two empirical constants by using the experimental results. Once best fit values of these coefficients are obtained, the correlation predicts the correct trend of the evolution in heat transfer coefficient with $U$ and $G$.

The initial set of equations of Golriz and Grace, overestimates the experimental results by a factor of about three. A very good fit is obtained with a modified expression for $G_{s h}$.

When applying a packet renewal mechanism to predict the heat transfer coefficient, the definition of a contact time on the basis of particle velocities in the riser, highly different in function of the riser operating regime, appears to predict heat transfer coefficient values of the correct order of magnitude. Further research coupling heat transfer measurements and particle contact times (as measured by Positron Emission Particle Tracking) are needed to improve the renewal approach.

\section{Acknowledgements}

This work was partly developed in the frame of the CSP2 European project. Authors acknowledge the European Commission for co-funding the "CSP2" Project-Concentrated Solar Power in Particles - (FP7, Project No. 282 932). It is also partly supported by the UK Engineering and Physical Science Research Council (EPSRC grant number: EP/F061439/1), and by the National Natural Science Foundation of China (Grant Nos. 51176110 and 51071184). The authors gratefully acknowledge support and advice from Prof. G. Cacères (Faculdad de Ingenierià y Ciencias, Universidad Adolfo Ibánez, Santiago, Chile), and Prof. Z. Tamainot Telto of the School of Engineering, University of Warwick, Coventry, UK.

\section{References}

[1] Fernandes D, Pitié F, Caceres G, Baeyens J. Thermal energy storage: how previous findings determine current research priorities. Energy 2012;39:246-57.

[2] Pitié F, Zhao CY, Cáceres G. Thermo-mechanical analysis of ceramic encapsulated phase-change-material (PCM) particles. Energy Environ Sci 2011;4:2117-24.

[3] Joulin A, Younsi Z, Zalewski L, Lassue S, Rousse DR, Cavrot J-P. Experimental and numerical investigation of a phase change material: thermal-energy storage and release. Appl Energy 2011;88:2454-62.

[4] Li M, Wu Z, Tan J. Properties of form-stable paraffin/silicon dioxide/expanded graphite phase change composites prepared by sol-gel method. Appl Energy 2012;92:456-61.

[5] Castell A, Belusko M, Bruno F, Cabeza LF. Maximisation of heat transfer in a coil in tank PCM cold storage system. Appl Energy 2011;88:4120-7.

[6] Martin V, He B, Setterwall F. Direct contact PCM-water cold storage. Appl Energy 2010;87:2652-9.

[7] Rady M. Thermal performance of packed bed thermal energy storage units using multiple granular phase change composites. Appl Energy 2009;86:2704-20.

[8] Oró E, de Gracia A, Castell A, Farid MM, Cabeza LF. Review on phase change materials (PCMs) for cold thermal energy storage applications. Appl Energy 2012:99:513-33.

[9] Zhou D, Zhao CY, Tian Y. Review on thermal energy storage with phase change materials (PCMs) in building applications. Appl Energy 2012;92:593-605.

[10] Borreguero AM, Luz Sánchez M, Valverde JL, Carmona M, Rodríguez JF. Thermal testing and numerical simulation of gypsum wallboards incorporated with different PCMs content. Appl Energy 2011;88:930-7.

[11] Tay NHS, Belusko M, Bruno F. Experimental investigation of tubes in a phase change thermal energy storage system. Appl Energy 2012;90:288-97.

[12] Pavel PM, Constantinescu M, Anghel EM, Olteanu M. Solidification of a PEG 1500-epoxy nanocomposite around a horizontal pipe. Appl Energy 2012;89:482-9.

[13] Medrano M, Yilmaz MO, Nogués M, Martorell I, Roca J, Cabeza LF. Experimental evaluation of commercial heat exchangers for use as PCM thermal storage systems. Appl Energy 2009;86:2047-55.

[14] Lamberg P. Approximate analytical model for two-phase solidification problem in a finned phase-change material storage. Appl Energy 2004;77:131-52.

[15] European Union. 7th. Framework program for research and technical development CSP2 concentrated solar power in particles. EU Grant Reference: 282932; 2011.

[16] Mahmoudi S, Chan CW, Brems A, Seville JPK, Baeyens J. Solids flow diagram of a CFB riser using Geldart B-type powders. Particuology 2012:10:51-61.

[17] Chan CW, Seville JPK, Parker DJ, Baeyens J. Particle velocities and their residence time distribution in the riser of a CFB. Powder Technol 2010;203:187-97.

[18] Ouyang S, Potter OE. Consistency of circulating fluidized bed experimental data. Ind Eng Chem Res 1993;32:1041-5.

[19] Chan CW, Seville JPK, Yang Z, Baeyens J. Particle motion in the CFB riser with special emphasis on PEPT-imaging of the bottom section. Powder Technol 2009;196:318-25.

[20] Smolders K, Baeyens J. Gas fluidized beds operating at high velocities: a critical review of occurring regimes. Powder Technol 2001;119:269-91.

[21] Smolders K, Baeyens J. Hydrodynamic modelling of the axial density profile in the riser of a low-density circulating fluidized bed. Can J Chem Eng 2001;79:422-9.

[22] Baeyens J, Geldart D. Modelling approach the effect of equipment scale on fluidized bed heat transfer data. J Powder Bulk Solids Technol 1980;4:1-9.

[23] Chen JC, Grace JR, Golriz MR. Heat transfer in fluidized beds: design methods. Powder Technol 2005:150:123-32.

[24] Muzyka DW. Use of probabilistic multiphase flow equations in the study of the hydrodynamics and heat transfer in gas-solids suspensions. Ph.D. thesis. University of Western Ontario; 1985.

[25] Grace JR. Heat transfer in high velocity fluidized beds. In: Hetsroni G, editor. Heat transfer 1990, vol. 4. New York: Hemisphere; 1990. p. 329-39.

[26] Molodtsof Y, Muzyka DW. General probabilistic multiphase flow equations for analyzing gas-solids mixtures. Int J Eng Fluid Mech 1989;2:1-24.

[27] Golriz M, Grace JR. Predicting heat transfer in large-scale CFB boilers. In: Grace JR, Zhu J, de Lasa HI, editors. Circulating fluidized bed technology VII. Ottawa, ON, Canada: Canadian Society for Chemical Engineering; 2002. p. 121-8.

[28] Lints MCL, Glicksman LR. The structure of particle clusters near the wall of a circulating fluidized bed. In: Weimer AW, editor. Fluid-particle processes, vol. 89. New York (NY): American Institute of Chemical Engineers; 1993. p. 35-52.

[29] Carslaw HS, Jaeger JC. Conduction of heat in solids. Oxford [Oxfordshire]: Oxford University Press; 1986.

[30] Gnielinski V. Fundamentals of heat and mass transfer. Fundamentals of heat and mass transfer. Hoboken (NJ): John Wiley; 2007. pp. 514-5.

[31] Everaert K, Baeyens J. Smolders K. Heat transfer from a single tube to the flowing gas-solid suspension in a CFB riser. Heat Transfer Eng 2006;27:66-70.

[32] Mahmoudi S, Seville JPK, Baeyens J. The residence time distribution and mixing of the gas phase in the riser of a circulating fluidized bed. Powder Technol 2010;203:322-30. 